\title{
EL COMERCIO DE ESTAMPAS ENTRE ROMA Y ESPAÑA A FINALES DEL SIGLO XVI: EL CASO DEL MERCADER ITALIANO ANTONIO PISANO
}

\author{
María Josefa Tarifa Castilla ${ }^{1}$ \\ Universidad de Zaragoza
}

\begin{abstract}
El presente estudio revela la llegada al norte de España de estampas y libros adquiridos en Roma en el viaje realizado entre 1582 y 1583 por el italiano Antonio Pisano, financiado gracias a la compañía mercantil temporal establecida entre éste y el genovés Juan Luis de Musante, maestro mayor de obras reales de Felipe II en Navarra, residentes en Pamplona. Grabados de temática sacra y profana realizados por destacados artistas de la época, como el holandés Cornelis Cort y los mantuanos Adamo y Diana Ghisi, además de libros de figuras, algunos de artistas tan sobresalientes como Michelangelo o Polidoro da Caravaggio.

Palabras clave: Grabados; libros; Roma; Navarra; Cornelis Cort; Ghisi; Michelangelo; Polidoro da Caravaggio; siglo XVI; comercio.
\end{abstract}

\section{TRADE OF ENGRAVINGS AND BOOKS BETWEEN ROME AND SPAIN AT THE END OF THE 16TH} CENTURY: THE CASE OF THE ITALIAN MERCHANT ANTONIO PISANO

This study reveals the arrival of prints and books to the North of Spain acquired by the Italian merchant Antonio Pisano in Rome during a trip of 1582-1583. The voyage was financed thanks to the temporary commercial company established between Pisano and the Genoese Juan Luis de Musante, royal master-builder to Felipe II in Navarre, and both residents in Pamplona. The works include engravings of sacred and profane themes by the most important engravers of the epoch, such as the Dutch Cornelis Cort and the Mantuans Adamo and Diana Ghisi, in addition to books of figures, some by outstanding artists such as Michelangelo or Polidoro da Caravaggio.

Key words: Engravings; books; Rome; Navarre; Cornelis Cort; Ghisi; Michelangelo; Polidoro da Caravaggio; XVI century; trade.

Como citar este artículo/Citation: Tarifa Castilla, María Josefa (2017): "El comercio de estampas entre Roma y España a finales del siglo XVI: el caso del mercader italiano Antonio Pisano". En: Archivo Español de Arte, vol. 90, núm. 357, Madrid, pp. 49-66; doi: 10.3989/aearte.2017.04.

\section{La presencia de un gran bibliófilo en Navarra a fines del siglo XVI}

Juan Luis de Musante y Rubiano es uno de los pocos artistas italianos que encontramos trabajando en Navarra en el último tercio del siglo XVI. La llegada a Pamplona de este genovés se produjo en 1575 para desempeñar el prestigioso cargo de maestro mayor de obras reales al servicio del monarca Felipe II, ocupándose principalmente de la dirección de la edificación de la ciudadela hasta su fallecimiento en 1587 , de acuerdo al diseño trazado en 1571 por el ingeniero

\footnotetext{
1 mjtarifa@unizar.es / ORCID iD: http://orcid.org/0000-0001-7723-2238.
} 
italiano Jacobo Palear Fratín ${ }^{2}$. También fue el responsable de acometer las mejoras arquitectónicas de los palacios reales de Pamplona (1575-1578) y Olite (1582-1585) promovidas por los virreyes $^{3}$, destacando igualmente en su faceta de tracista, proporcionando los planos para la edificación del nuevo monasterio de Leyre $(1578-87)^{4}$ y para la ampliación de la cabecera y crucero de la parroquia de Lerín, ejemplo sobresaliente de arquitectura clasicista en el ámbito geográfico navarro, que refleja el conocimiento que Musante poseía de la tratadística italiana contemporánea, principalmente de Vignola y Palladio ${ }^{5}$.

Artista italiano que además sobresalió con respecto a sus contemporáneos en el marco de la Navarra del siglo XVI por la posesión de una de las bibliotecas más nutridas y voluminosas de su tiempo, en lo que se refiere a artistas que desarrollaron su actividad fuera del ámbito cortesano, formada por 114 volúmenes dedicados a la tratadística artística, las matemáticas, la geometría, la aritmética, la perspectiva o la fortificación, entre otras disciplinas históricas, filosóficas y científicas ${ }^{6}$.

El hallazgo de documentación inédita en el Archivo Real y General de Navarra permite aportar información novedosa referente a la compañía mercantil establecida a comienzos de la década de 1580 entre Musante y Antonio Pisano, un italiano avecindado en Pamplona al servicio de aquel, con objeto de comprar un importante volumen de grabados en Roma para venderlos posteriormente en España.

\section{La adquisición de estampas y libros en Italia}

A su llegada a la capital del reino navarro en $1575^{7}$, Juan Luis de Musante traía consigo unos 25 libros, algunos de su profesión, otros de filosofía y diversas materias, principalmente escritos en italiano ${ }^{8}$, cifra que triplicó a comienzos de la década de 1580 con la adquisición de nuevos ejemplares ${ }^{9}$. La compra de algunos de estos volúmenes la encomendó a Antonio Pisano, personaje del que a día de hoy no sabemos mucho. Residente en Pamplona desde al menos 1571, cuanto contaba con unos 20 años, moraba en una casa próxima al palacio del virrey, junto con su esposa Juana de Urdax ${ }^{10}$. En la documentación consultada, Pisano nunca aparece identificado o adscrito a un oficio concreto, si bien en algún caso lo hallamos dedicado al trato o compraventa de mercancías entre España e Italia, como es el caso que nos ocupa, o también prestando sus servicios a otras personalidades navarras con objeto de resolver algún asunto en la península itálica. Ejemplo de ello es el viaje que Pisano emprendió a Milán en septiembre de 1599 por encargo de Fermín de Huarte y Mendicoa, señor de los palacios de Zulueta y Otano, para localizar a su agente, Juan Royo, ante la mala gestión que estaba haciendo de sus negocios, desplazamiento en el que invirtió quince meses ${ }^{11}$.

Por lo que respecta a su relación con el artista genovés, Pisano conoció a Juan Luis de Musante en $1575^{12}$, aunque desconocemos en qué circunstancias, forjándose desde entonces una estrecha amistad. En julio de 1582 Pisano proyectó un viaje a Italia, ya que se había concertado con Martín de Zubialde, para procurarle "en Roma una capilla o altar privilegiado y un jubileo

Tarifa Castilla, 2011a: 583-602; 2015: 528-530.

3 Tarifa Castilla, 2013: 889-906.

4 Tarifa Castilla, 2008: 610-613.

5 Tarifa Castilla, 2009: 10-12 y 18-29; 2010: 187-188 y 192-194.

6 Tarifa Castilla, 2011b: 31-46.

7 Sobre la actividad profesional de Musante en otras localidades hispanas antes establecerse en Navarra, véase Gómez-Ferrer Lozano, 2013: 43-60.

${ }^{8}$ Archivo General de Navarra (AGN), Tribunales Reales (TR), Procesos (Pr), Sig. 224099, ff. 98v-99r.

9 AGN, TR, Pr, Sig. 224054, f. 108v.

${ }^{10}$ AGN, TR, Pr, Sig. 224054.

11 AGN, TR, Pr, Sig. 100095.

12 AGN, TR, Pr, Sig. 224099, f. 53r. 
para la yglesia de Abaurrea", localidad navarra de la que éste era vecino ${ }^{13}$. Aprovechando este desplazamiento, el italiano también se encargaría de "otros negocios suyos de cobranças de ciertas cantidades que havia quedado deviendo en esta ciudad [de Roma] a un criado del Principe Vespasiano llamado Atillo Dalfino"14, es decir, a un sirviente de Vespasiano Gonzaga, duque de Trayeto y marqués de Sabbioneta.

Pisano solicitó ayuda económica a Musante para realizar este traslado, entregándole el genovés 300 ducados que aquel emplearía en la compra de algunas mercadurías que vendería a lo largo del camino, devolviéndole a su regreso la referida cantidad, así como parte de la ganancia conseguida. Por tanto, una compañía mercantil formada únicamente por dos socios, con capital propio y de carácter temporal. Juan Luis además le encargó la adquisición de ciertos libros para su biblioteca y le solicitó que en Génova entregase unas cartas a personas que le debían dinero, localidad italiana en la que debía recoger a su sobrino, Juan Bautista Musante, que residía en Savona, para traerlo consigo a Pamplona ${ }^{15}$.

La rigurosa contabilidad y anotaciones realizadas por Pisano desde el inicio del viaje en julio de 1582 hasta su regreso a la capital del reino navarro el 12 de octubre de 1583, permiten recomponer con gran fidelidad la duración del mismo, las distintas ciudades que visitó, así como las diversas mercancías que compró y vendió, desde utensilios, textiles, joyas, adornos, herramientas de trabajo, libros, estampas o dibujos iluminados ${ }^{16}$. Negocio de importación de grabados y libros de estampas desde Italia que fue sumamente significativo para la difusión de la cultura artística del renacimiento en nuestro país, al que, por ejemplo, también se dedicó el pintor italiano y comerciante Pietro Paolo de Montalbergo en Barcelona, desde 1548 hasta su fallecimiento en $1588^{17}$.

Pisano salió de Pamplona el 17 de julio de 1582 con dirección a Barcelona, donde adquirió en agosto distintos artículos para comerciar con ellos a lo largo del viaje, como guantes de cordobán, tijeras de sastre, tijeras y lancetas de barbero, peines labrados o navajas que guardó en un baúl, objetos que fue vendiendo en su periplo por mar en las localidades costeras de Marsella, Villafranca del Mar, Mónaco, Génova y las interiores de Parma y Bolonia, por los que obtuvo 2.249 reales $^{18}$. Desde Parma se dirigió al ducado de Sabbioneta, donde visitó al señor Vespasiano Gonzaga ${ }^{19}$, uno de los hombres de gobierno y militares de confianza de Felipe $\mathrm{II}^{20}$, al que Pisano seguramente conocía personalmente, ya que entre 1572 y 1575 había desempeñado el cargo de virrey de Navarra ${ }^{21}$, residiendo durante estos años en Pamplona.

Pisano llegó a Roma el 17 de noviembre de 1582, donde permaneció tres meses y cuatro días. Durante su estancia mercó una serie de efectos para llevar a España, algunos de los cuales los cambió por "papeles flamengos y otros curiosos" que traía consigo. Entre ellos sobresale la adquisición de hojas de papel de distintas dimensiones, que cuantificó en 7.342 pliegos, "que son libros diversos de figuras y otros quartos diferentes" 22 .

De gran interés resultan para nuestro estudio las numerosas estampas que compró, algunas sueltas, otras formando parte de series de grabados y álbumes, como "doze Romas grandes" por 36 reales $^{23}$, es decir, ilustraciones de la urbe romana de cierto tamaño, ya que cada vista completa ocupaba seis pliegos, en las que se mostrarían los edificios de la antigüedad insertos en el trazado urbano de la ciudad moderna. Entre los cuantiosos planos y vistas de la ciudad eterna

13 AGN, TR, Pr, Sig. 282591, f. 2r.

${ }^{14}$ AGN, TR, Pr, Sig. 282591, f. 2r.

15 AGN, TR, Pr, Sig. 282591, f. 2v.

${ }^{16}$ Un estudio sobre los diferentes artículos con los que se comerciaba en la Europa del siglo XVI es el de Rivero Gracia, 2005: 1-53.

17 Garriga Riera, 1999, vol. II: 5-40.

18 AGN, TR, Pr, Sig. 282591, ff. 8v-10r.

19 AGN, TR, Pr, Sig. 282591, f. 16v.

20 Hernando Sánchez, 1999: 263-264. Civale, 2010: 163-206.

21 Bosch, 2013: 1023-1094.

22 AGN, TR, Pr, Sig. 282591, f. 13r.

23 AGN, TR, Pr, Sig. 282591, f. 11r. 
impresos en el siglo XVI, y con anterioridad a 1583, se encuentran el plano inserto en 1544 en la segunda edición del libro Urbis Romae Topographia de Bartolome Marliano, el grabado realizado por el artista francés Nicolás Beatrizet con la vista aérea de la urbe desde el oeste para el editor Antonio Lafrery en 1557, que quedó incluida en la obra Speculum Romanae Magnificentiae, o los grabados de Francesco Paciotti (1577) o Mario Cartaro (1576), entre otros ${ }^{24}$. Por su parte, otra de las estampas de la ciudad que alcanzó gran difusión fue la inserta en 1572 en el primer volumen de la célebre obra cartográfica Civitatis Orbis Terrarum ${ }^{25}$ (Colonia, 1572-1617), editada por Georg Braun en seis volúmenes, el más completo elenco de vistas panorámicas, planos y comentarios textuales de ciudades de todo el mundo publicado durante la Edad Moderna, con más de 500 ciudades representadas diseñadas por Joris Hoefnagel y grabadas por Franz Hogenberg.

Dado que las estampas escogidas por Pisano de Roma eran de tamaño grande, puede que se tratase del grabado realizado por Leonardo Buffalini en 1551 formado por 12 planchas $^{26}$, o de la "Pianta grande" que Pirro Ligorio (1513-1583) ${ }^{27}$, arquitecto, pintor y anticuario napolitano publicó en 1561 de la Roma Antigua con Michele Tramezzino formada por 12 láminas $^{28}$, con múltiples indicaciones topográficas y toponímicas ${ }^{29}$. Imagen que fue tomada como punto de partida por Étienne Dupérac para grabar una planta grande de Roma, publicada en la misma ciudad el 1 de abril de 1574, Urbis Romae Sciographia, compuesta por 9 planchas ${ }^{30}$.

Pisano también mercó diversos grabados de temática religiosa y profana y libros de figuras, materiales y modelos imprescindibles en el trabajo de los artistas ${ }^{31}$, permitiéndoles conocer la obra de autores como Rafael, Miguel Ángel, Tiziano y otros artífices de primera magnitud. Entre las estampas adquiridas por el italiano en Roma se encontraban "dos Resurectiones de a dos pliegos de muertos, diez adulteras, doze San Lorenços del Baccio retallados, onze bacanarias y una dozena de papeles de cavalicos cortados todos de la diana" 32 , esto es, grabados realizados por una artista manierista italiana llamada Diana Scultori Ghisi (1535-1587). Perteneciente a la escuela del boloñés Marcantonio Raimondi en Roma, el principal grabador de los dibujos de Rafael $^{33}$, Diana es una de las pocas mujeres artistas que Vasari menciona en la edición de 1568 de sus Vidas $^{34}$. Hija del artista mantuano Giovanni Battista Scultori (1503-1575) ${ }^{35}$, quien le enseñó a dibujar y la técnica del grabado, formó parte del círculo artístico que tuvo su desarrollo en Mantua, si bien a partir de 1575 se estableció en Roma donde tuvo taller propio y firmó sus obras con su nombre.

De su amplia producción ${ }^{36}$, uno de los trabajos más conocidos es un grabado a buril realizado en 1575 con el tema de Jesús y la mujer Adúltera, basado en un dibujo de Giulio Romano ${ }^{37}$ (fig. 1), uno de los pintores que más reprodujo Diana, y que sospechamos es el mismo grabado que consiguió Pisano en Roma, del que se trajo una decena de ejemplares.

De esta misma artista italiana Pisano escogió 12 grabados de San Lorenzo del "Baccio retallados", es decir, de estampas con la representación de este santo sobre idea del florentino Baccio

\footnotetext{
24 Insolera, 1996: 124-138.

25 Switf, 2008: 204-207.

26 Insolera, 1996: 112-123.

27 Pinci, 1992. Coffin, 2003.

28 Labrot, 1987: 203. Burns, 1988: 19-92.

29 Frutaz, 1962, vol. II, tav. 30.

30 Labrot, 1987: 203.

31 Véase, por ejemplo, Silva Maroto, 1991: 311-210.

32 AGN, TR, Pr, Sig. 282591, f. 11r.

33 González de Zárate, 1999: 118-125.

34 Vasari, 1568, secondo volumen de la terza parte: 558.

35 Sobre este grabador, véase Massari, 1980: 20-26.

36 Massari, 1980: 79-116.

37 Massari, 1980: 97-98 y 260-261. Boorsch/Spike, 1986: 242.
} 


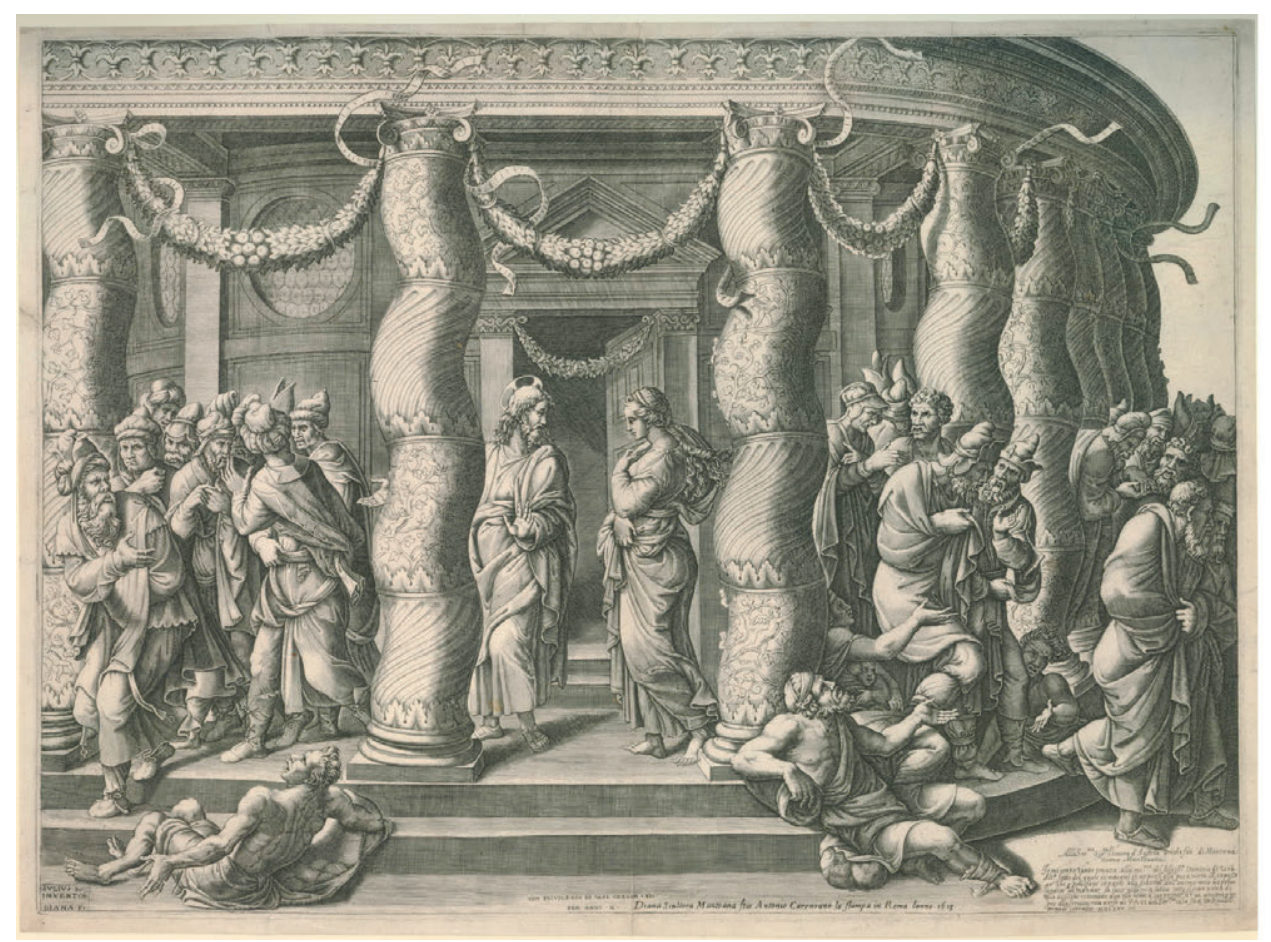

Fig. 1. Diana Scultori Ghisi. Jesús y la mujer adúltera. Londres, British Museum.

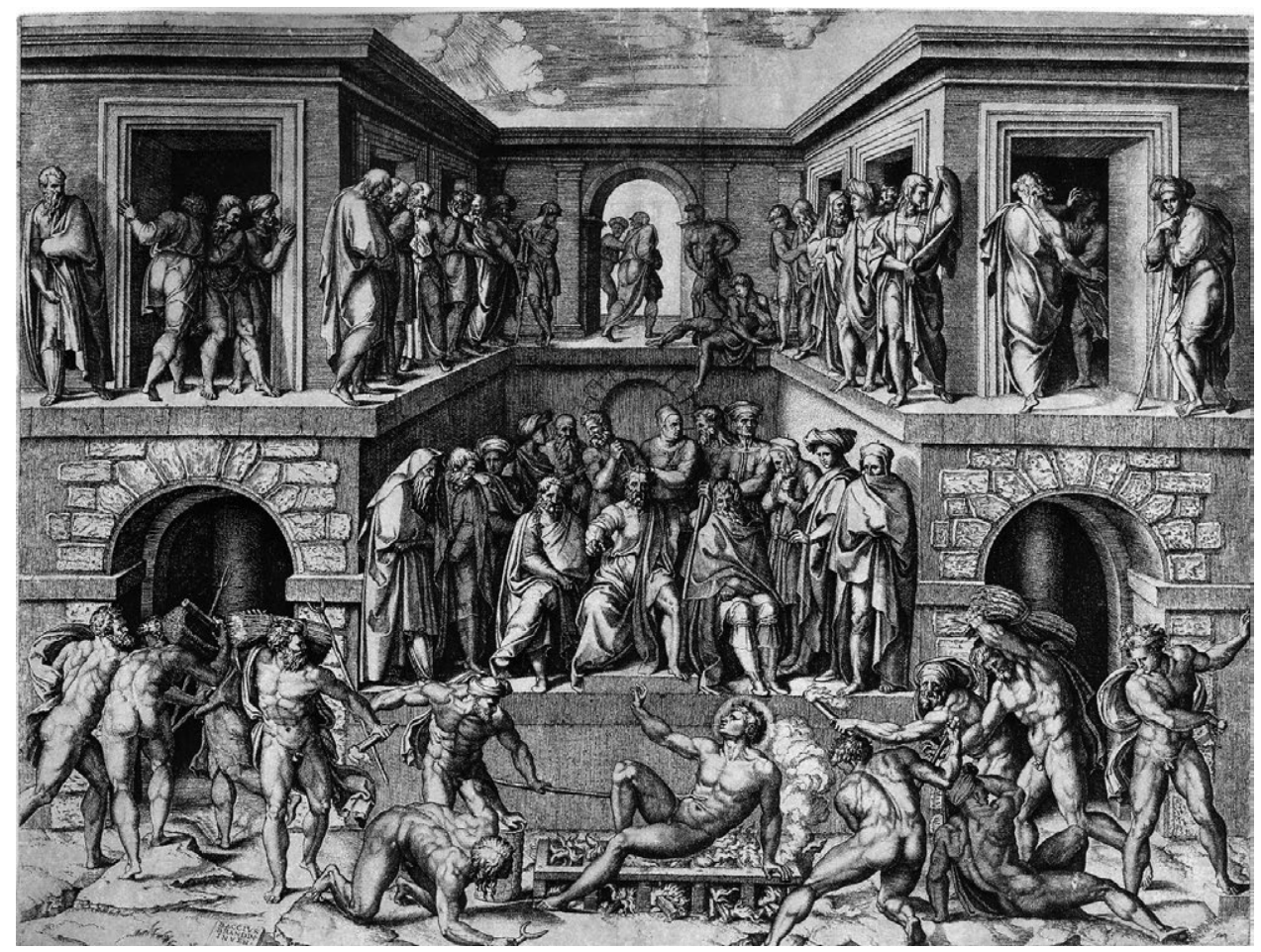

Fig. 2. Diana Scultori Ghisi. Martirio de San Lorenzo, según grabado de Marcantonio Raimondi. Londres, British Museum. 


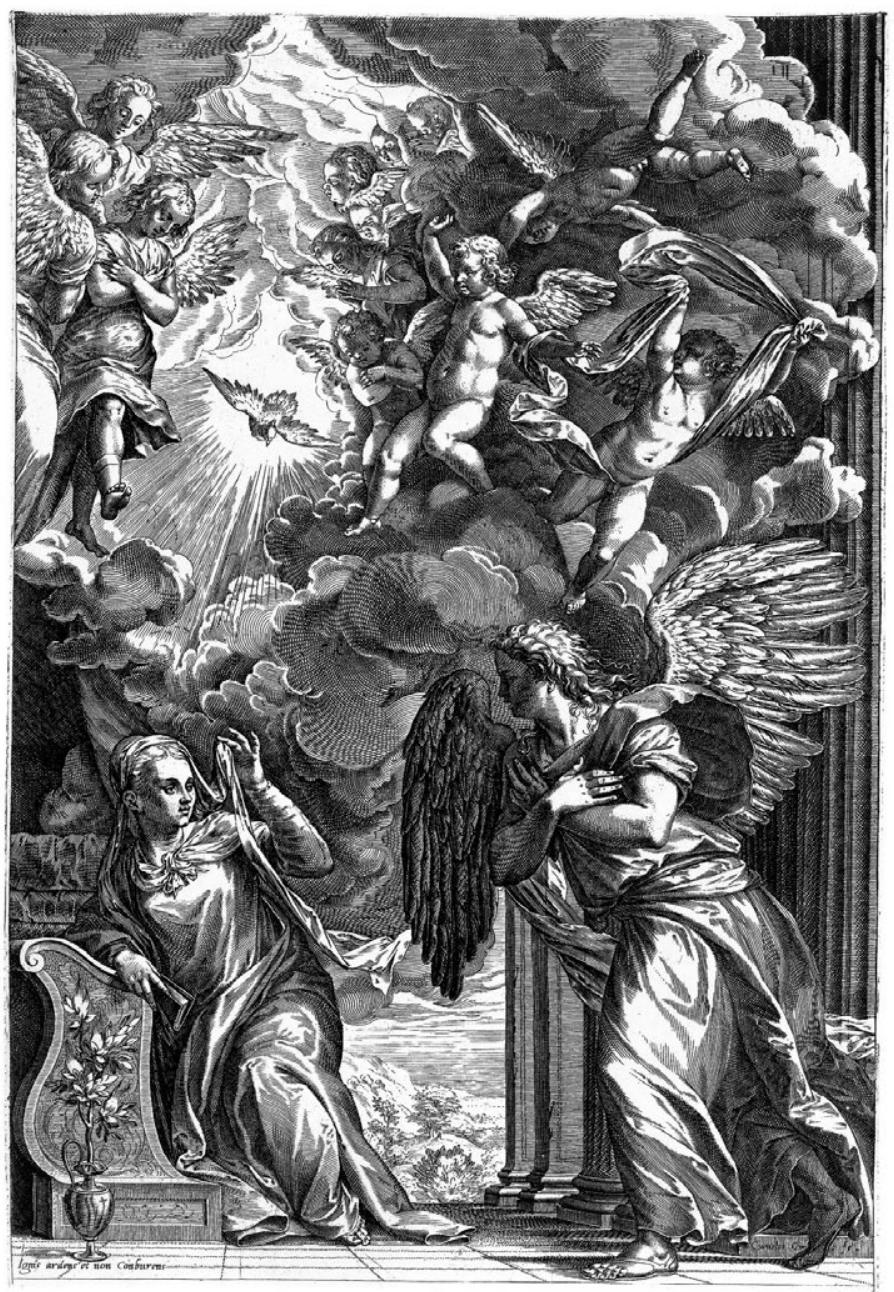

Fig. 3. Cornelis Cort. $L a$ Anunciación, según el cuadro de Tiziano de la iglesia de El Salvador de Venecia. Londres, British Museum.

Bandinelli $(† 1560)^{38}$, escultor, pintor y según Vasari excelente dibujante ${ }^{39}$, que trabajó para los Médicis y los Papas. Baccio tenía por costumbre encargar grabados de algunas de sus obras, como el Martirio de San Lorenzo (ca. 1525) concebida como fresco para las paredes del coro de la iglesia de San Lorenzo de Florencia, que le grabó Marcantonio Raimondi ${ }^{40}$, la mejor de sus hojas de los años veinte alcanzando una amplia difusión, siendo, por ejemplo, empleada por el pintor flamenco Daniel Martínez (1575-†1636) en la escena del banco del mismo tema del retablo de la parroquia de la Asunción de Sádaba (Zaragoza) ${ }^{41}$. En la referida estampa de Raimondi con el suplicio del santo se inspiró Diana para realizar el grabado con el mismo tema en 1582 (fig. 2) ${ }^{42}$. Asimismo, Pisano se hizo con dos grabados de la resurrección de los muertos de esta artista, once estampas de bacanales y una docena sobre caballos, sin que podamos precisar más al respecto.

\footnotetext{
38 Pijoán, 1966: 204-25.

39 Vasari, 1998, vol. VI: 133-197.

40 Vasari, 1998, vol. VI: 147. Gnann, 1999: 358-359.

${ }^{41}$ Criado Mainar, 2013: 297-299.

${ }^{42}$ Massari, 1980: 111-112 y 276-277. Boorsch/Spike, 1986: 268.
} 


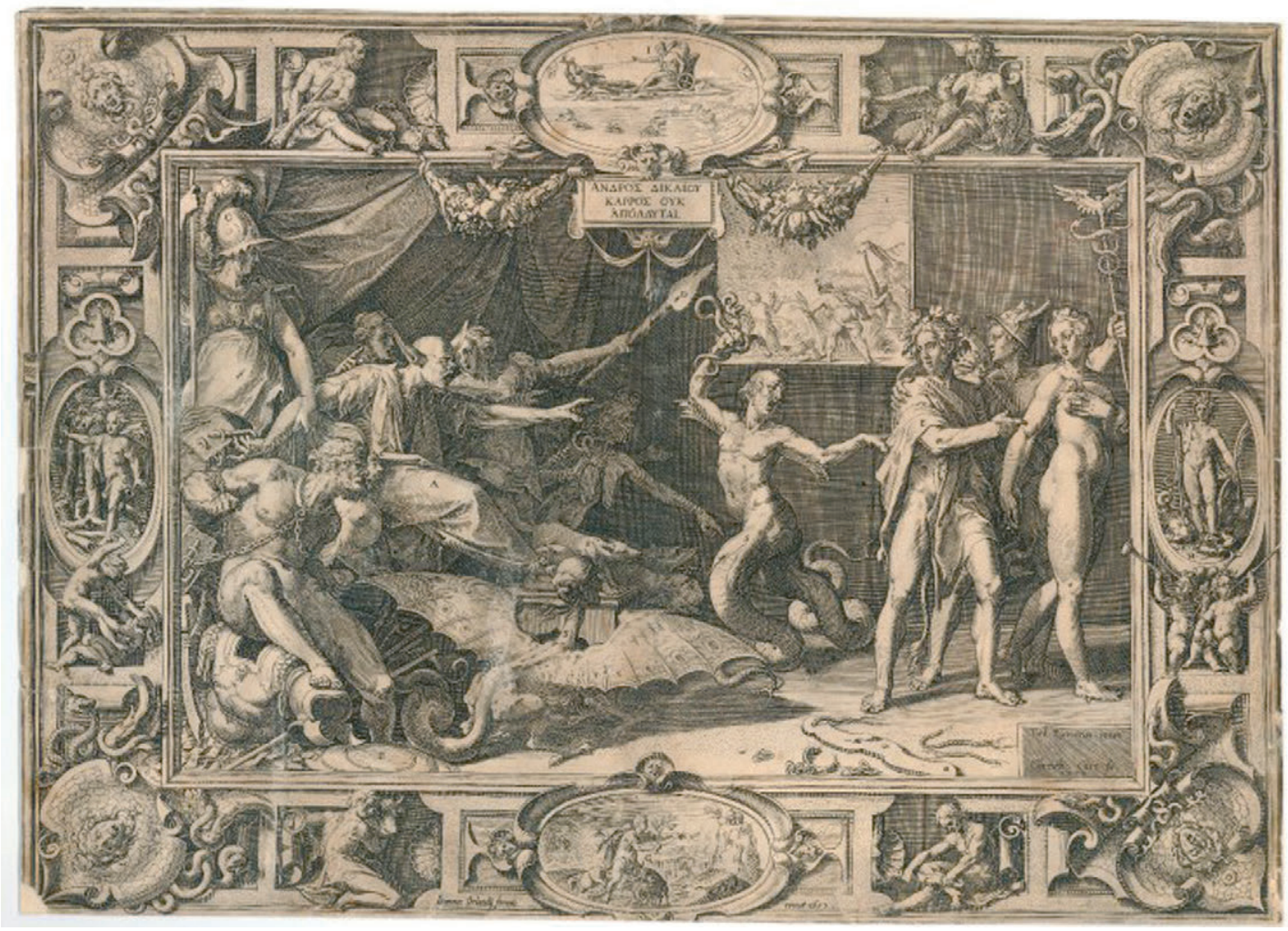

Fig. 4. Cornelis Cort. La Calumnia de Apeles, sobre dibujo de Federico Zuccaro. Londres, British Museum.

También adquirió el mercader italiano dos anunciaciones, cuatro calumnias y cuatro estampas de San Lorenzo "con otros ocho pliegos diferentes de Cornelio" 43 , que identificamos con el grabador holandés Cornelis Cort (1533-1578) ${ }^{44}$, quien pasó a la plancha numerosas composiciones de artistas como Tiziano, Rafael Sanzio, Giulio Clovio, Federico Barocci o Girolamo Muziano. Un artista con una producción muy notable, cuyas estampas se estiman en más de 400, hasta el punto de ser considerado uno de los grabadores mejor representados en los inventarios de artistas del siglo XVI, como es el caso de El Greco ${ }^{45}$. Entre los grabados que Cort llevó a cabo con el tema de la Anunciación, destacan las estampas realizadas sobre composiciones de Giulio Clovio $(1576)^{46}$, así como de Tiziano, por ejemplo el cuadro de la iglesia de El Salvador de Venecia (1565) que grabó hacia 1566 con los ángeles invertidos en la parte superior ${ }^{47}$ (fig. 3), obra que acometió bajo la dirección del pintor veneciano.

Por lo que respecta a las estampas de la calumnia, probablemente se refiera a la que realizó Cort de este asunto en 1572 sobre el dibujo de Federico Zuccaro, alusivo a La Calumnia de Apeles $^{48}$ (fig. 4). En el caso de los cuatro grabados de San Lorenzo, uno de los ejemplares más conocidos del holandés sobre este tema es El Martirio de San Lorenzo según modelo de Tiziano,

43 AGN, TR, Pr, Sig. 282591, f. 11r.

44 González de Zárate, 1993, vol. III: 53-57.

45 Docampo/Riello, 2014: 86-107.

46 Strauss/Shimura, 1986: 30. Hollstein, 1993, vol. V: 41.

47 Huidobro/González Negro, 2001: 69. Huidobro/Tomé Virseda, 2004: 222.

48 Bierens de Haan, 1948: 219. Strauss/Shimura, 1986: 250. González de Zárate, 1993, vol. III: 121. Hollstein, 1993, vol. V: 58. 


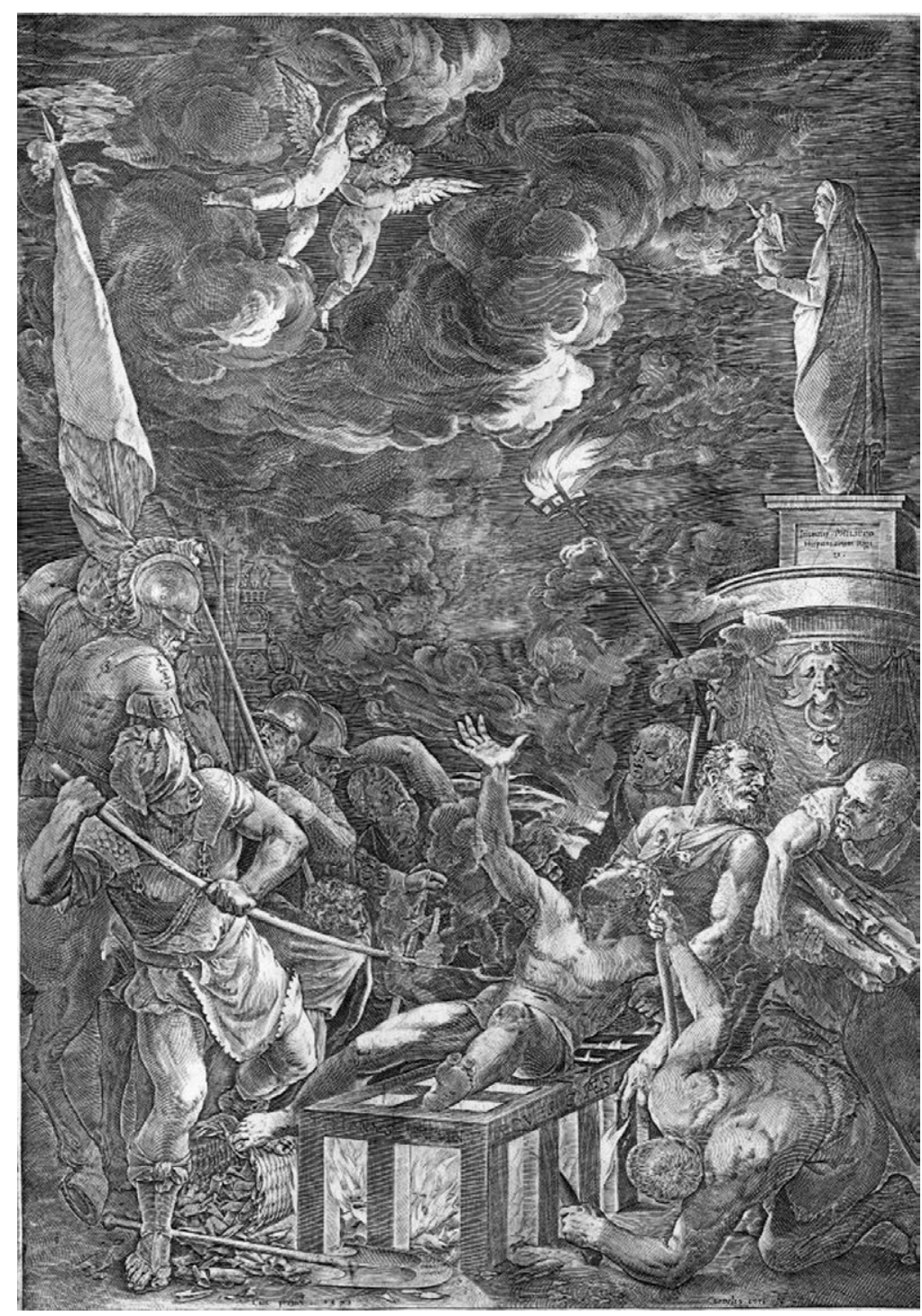

Fig. 5. Cornelis Cort, Martirio de San Lorenzo, según modelo de Tiziano. Londres, British Museum.

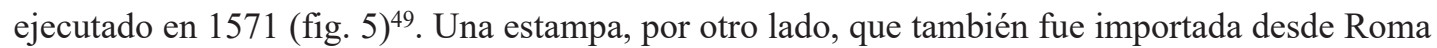
por el anteriormente aludido pintor italiano Pietro Paolo de Montalbergo a Barcelona en 1582, ya que de Cort trajo 165 estampas de San Lorenzo, entre ellas la del referido martirio ${ }^{50}$.

Pisano también se hizo con 33 pliegos "de los paeses del muçiano", a real y medio el pliego ${ }^{51}$, esto es, de Girolamo Muziano (†Roma 1592) ${ }^{52}$, un pintor manierista del área veneciana, formado con Romanino, seguidor de Tiziano, que se instaló en Roma hacia 1550, donde fue conocido como Il Giovan dei paesi, por su especialización en el paisaje. De hecho, de su producción artística destacan las pinturas que realizó al fresco junto a Federico Zuccaro en la Villa d'Este, en los que también participó Cesare Nebbia. El mercader italiano también trajo 25 pliegos imperia-

\footnotetext{
49 Strauss/Shimura, 1986: 162. Hollstein, 1993, vol. V: 53. Bierens de Haan, 1948: 140.

${ }^{50}$ Garriga Riera, 1999, vol. II: 10.

51 AGN, TR, Pr, Sig. 282591, f. 11r.

52 Bénézit, 1966, vol. VI: 290-291. Freedberg, 1978: 499-502.
} 
les con el retrato del Papa Gregorio XIII ${ }^{53}$, 40 pliegos imperiales "de la filosofía y otra en tafetan amarillo guarneçida", y 60 docenas de cartillas estampadas "miniadas grosamente y bastardas" 54 .

Pisano además compró un importante volumen de publicaciones de materias variadas, especificando el inventario objeto de estudio que "todos los libros son de a quarto pliego y de figuras y no libros de lectura, sino [...] diez libros de Trasmudar la gulla de San Pedro", junto con otros seis volúmenes de esgrima ${ }^{55}$. Entre ellos encontramos 18 "libros de compartimentos", 10 tomos de materia jurídica titulados De Iuris Consultum, otra decena "del Rosaria" y 10 libros de emperadores. En el caso del libro del rezo del rosario, es probable que se tratase del Rosario della Sacratisima Virgine Maria, publicado en Roma en 1582 por Giuseppe de gl'Angeli, formado por 22 estampas que han sido atribuidas al destacado grabador mantuano Adamo Scultori ${ }^{56}$, al que nos volveremos a referir más adelante.

Con respecto al libro de los emperadores, Marcantonio Raimondi había realizado un repertorio con grabados sobre Los emperadores romanos, el cual a su vez tuvo eco en la serie que sobre dichos gobernantes realizó su discípulo Enea Vico bajo el título Le imagini con tutti riversi trovati et le vite de gli imperatori tratte delle medaglie et dalle historie de gli antichi (Venecia, $1548)^{57}$, ejemplares a los que quizás se refiera el documento. También hay otro volumen con esta temática realizado por el humanista flamenco, grabador, editor, pintor y numismático Hubertus Goltzius, Los vivos retratos de todos los Emperadores, desde Iulio Cesar hasta el emperador Carlos $V y$ don Fernando su hermano (Amberes, 1560) ${ }^{58}$, decorado con grabados de colores inspirados en las monedas almacenadas en las más famosas colecciones europeas de la época. Con posterioridad, Fulvio Orsini, uno de los grandes filólogos y humanistas del siglo XVI, publicó en Roma en 1570 la obra Imagines et elogia vivorum illustrium et eroditum, en la que se incluyeron un importante número de emperadores romanos junto a otros personajes de la antigüedad pertenecientes al mundo griego.

Especialmente interesante resulta la adquisición por parte de Pisano de los "diez libros de figuras de Miguelangelo" 59 , que deducimos se refiere a Michelangelo Buonarroti, es decir, 10 volúmenes impresos con ilustraciones de la obra del gran genio ${ }^{60}$, por los que el mercader pagó 100 reales, sin que el documento aporte más información al respecto. Quizás fuesen algunas de las estampas realizadas por Nicolás Beatrizet ${ }^{61}$, recordado principalmente por sus reproducciones de las obras de Miguel Ángel, como la formada por 10 planchas que acometió en 1562 sobre el Juicio Final de la Capilla Sixtina -que ensambladas medían en total 1,225 $\mathrm{mm} \times 1,055 \mathrm{~mm}^{62}$, fresco que con anterioridad había sido grabado por Niccolo della Casa y publicado por Antonio de Salamanca en 1543,1545 y $1548^{63}$.

También el mantuano Giorgio Ghisi (1520-1582), considerado por Bersier como uno de los más destacados alumnos de Marcantonio Raimondi' ${ }^{64}$, grabó con tan sólo 20 años algunas de las pinturas de Buonarroti. Producción artística que desarrolló a partir de 1540, tras su llegada a Roma y puesta en contacto con el francés Antonio Lafrery ${ }^{65}$, que le editó, según los estudios de

53 Una de las estampas con la imagen del Papa Gregorio XIII fue impresa en Roma en 1581 por el francés Antonio Lafrery, así como otro retrato rodeado por 36 representaciones de las obras de su pontificado. González de Zárate, 1994, vol. VII: 86.

${ }^{54}$ AGN, TR, Pr, Sig. 282591, f. 11v.

55 AGN, TR, Pr, Sig. 282591, ff. 11v-12r.

56 González de Zárate, 1999: 142-143.

57 Spike, 1985: 209. San Vicente/Santos Yanguas, 2005, vol. 1: 105-111. Miller, 1999: 135-138.

58 Goltzius, 1560.

59 AGN, TR, Pr, Sig. 282591, f. 11v.

60 Sobre los dibujos de Miguel Ángel, véase Tolnay, 1975-1980, 4 vols. Hirst, 1989. Joannides, 2003. Gnann, 2004.

${ }^{61}$ González de Zárate, 1993, vol. I: 13-115.

${ }_{62}$ Boorsch, 1982: 282-292. Bury/Lockett, 2011: 266-271.

63 Boorsch/Lewis/Lewis, 1985: 53-57.

${ }^{64}$ Bersier, 1990: 147.

${ }^{65}$ González de Zárate, 1999: 151-153. 

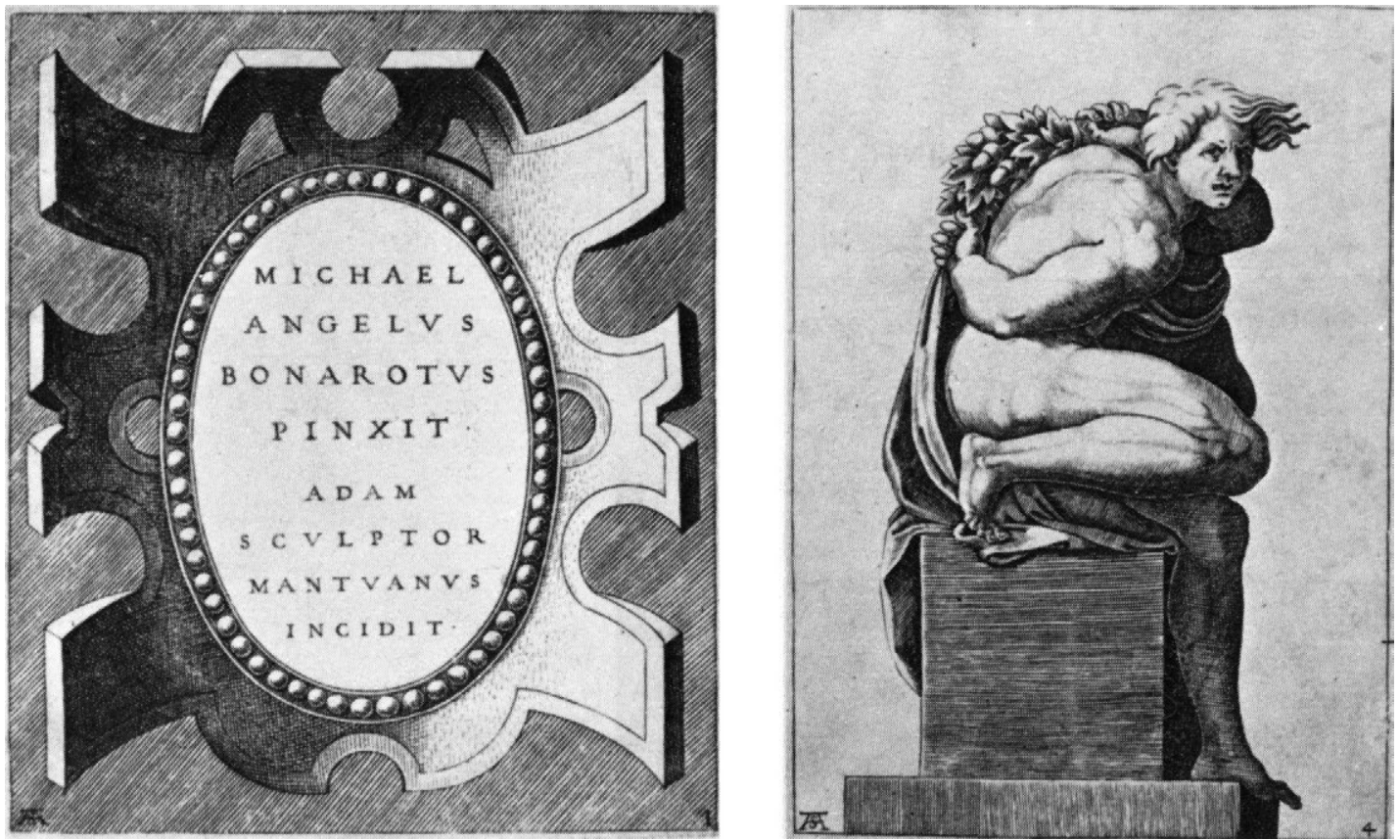

Fig. 6. Adamo Ghisi Scultori. Ignudi de la Capilla Sixtina de Roma según Miguel Ángel.

Boorsch y Lewis, 33 grabados ${ }^{66}$. Así, Ghisi acometió diferentes litografías de los frescos de la Capilla Sixtina, tanto de las pinturas que Miguel Ángel había realizado en el techo entre 1508 y $1512^{67}$, concretamente de los diferentes Profetas y las Sibilas ${ }^{68}$, donde en palabras de González de Zárate hizo gala de un sentido del dibujo poco común para la época transportando al grabado la grandeza y majestad que el genial artista consiguió en sus frescos ${ }^{69}$, como de la pintura del Juicio Final (1535-1541) que cubre la pared frontal ${ }^{70}$, que grabó en 10 planchas a mediados de la década de $1540^{71}$, con una gran maestría y calidad, como refiere Vasari en la edición de las Vidas de 1568.

Asimismo, a Adamo Ghisi Scultori (1530-1585), miembro de la importante familia de grabadores mantuanos cuyo padre fue Giovanni Battista Ghisi, se debe la serie grabada formada por 73 láminas siguiendo modelos de Miguel Ángel pertenecientes a las pinturas del techo de la Capilla Sixtina ${ }^{72}$, en torno a 1574, entre las que aparecen los ignudi o desnudos masculinos sentados en pedestales en complejas posturas (fig. 6), que flanquean las distintas escenas del Génesis, o las figuras de las sibilas que anuncian la caída del hombre, como la Líbica (fig. 7), Cumana, Délfica, Eritrea y Pérsica, y los profetas que anuncian la venida del Salvador, como Daniel, Isaías, Zacarías, Joel, Ezequiel, Jeremías y Jonás ${ }^{73}$. Precisamente, Antonio Pisano dejó a deber a Adamo Scultori 6 ducados en Roma "de tantos papeles que me dio fiado para pagarlos en Mantua a su madre" 74 , probablemente algunos de los referidos grabados que reproducen los frescos

\footnotetext{
${ }^{66}$ Boorsch/Lewis/Lewis, 1985.

67 Tolnay, 1985: 27-35.

${ }^{68}$ Massari, 1980: 127-130 y 306-311. Boorsch/Lewis/Lewis, 1985: 151- 165.

69 González de Zárate, 1994, vol. VI: 27.

70 Tolnay, 1985: 47-60.

71 Massari, 1980: 125-127 y 296-305. Boorsch/Lewis/Lewis, 1985: 53-57. Boorsch/Spike, 1986: 52-61 y 66-75.

72 Massari, 1980: 53-76 y 222-239. Boorsch/Spike, 1986: 180-195.

73 González de Zárate, 1999: 143.

74 AGN, TR, Pr, Sig. 282591, f. 22r.
} 
Fig. 7. Adamo Ghisi Scultori. Sibila Líbica de la Capilla Sixtina de Roma según Miguel Ángel.

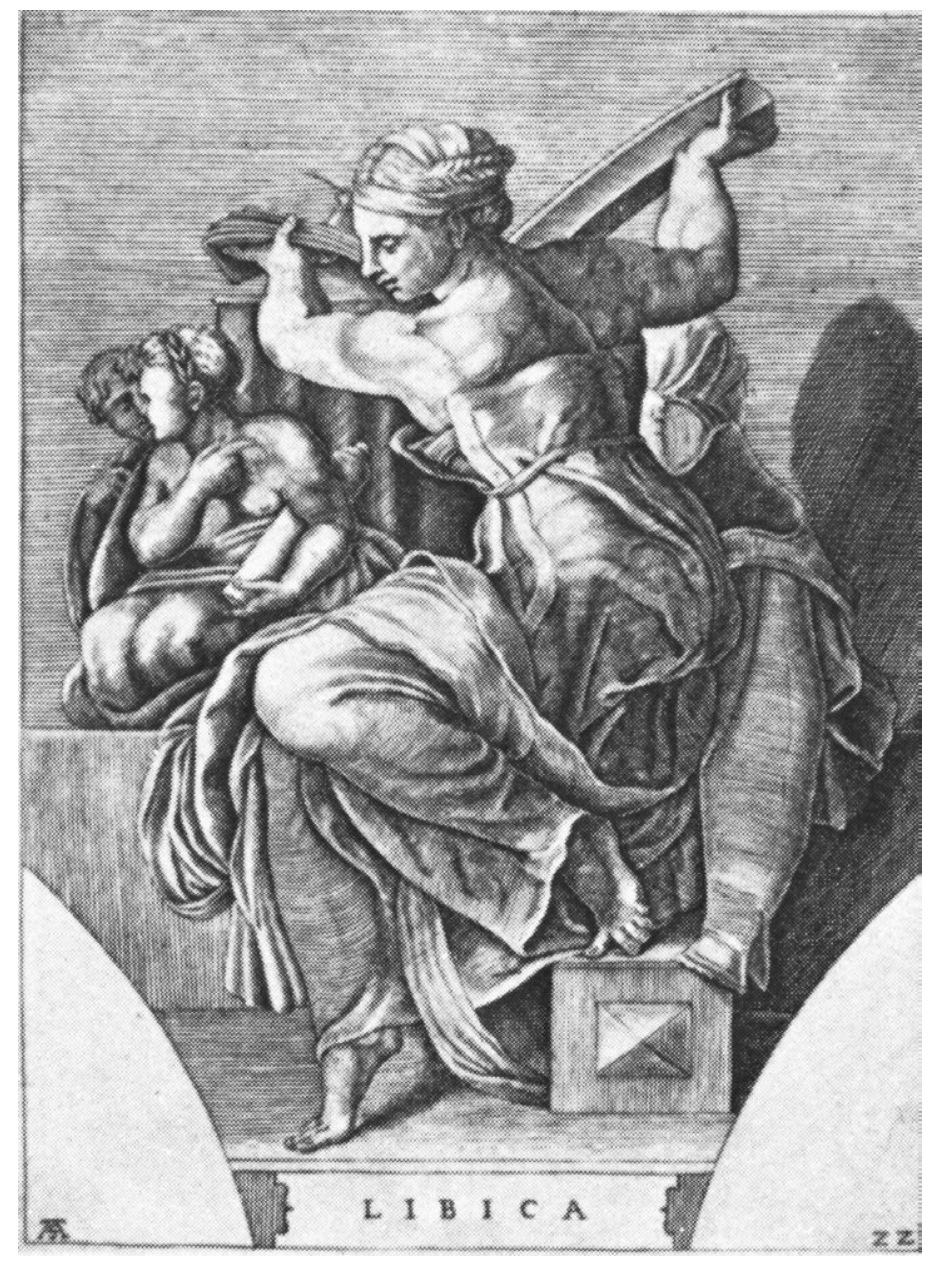

de la Sixtina. Por su parte, en el inventario de la biblioteca de Bernardino de Cárdenas, duque de Maqueda, que ha dado a conocer García Medina, también se documentaron los grabados "de un tal Michelangelo" realizados por Adamo Ghisi ${ }^{75}$, que entendemos es la misma serie del grabador mantuano a la que nos estamos refiriendo. Asimismo, los más destacados artistas que trabajaron en España en el siglo XVI poseyeron dibujos y estampas con las obras de Miguel Ángel, como Gaspar Becerrra, Esteban Jordán, Juan de Juni, que tenía un papel grande del Juicio Final ${ }^{76}$, al igual que el pintor Juan Claver, avecindado en Pamplona ${ }^{77}$ o Juan de Anchieta ${ }^{78}$.

Los flamencos también difundieron a través de sus grabados la obra del artista florentino, como Johann Wierix (1594-1618) con la estampa del Juicio Final ${ }^{79}$ o Cornelis Cort que reprodujo en 1570 las tumbas de Lorenzo y Giuliano de Médici para la sacristía nueva de la iglesia de San Lorenzo de Florencia ${ }^{80}$. La tumba del Papa Julio II en la iglesia de San Pietro in Vincoli

\footnotetext{
75 García Medina, 1999: 406.

76 Fernández del Hoyo, 1991: 339

77 Fernández Gracia/Echeverría Goñi/García Gainza, 2005: 287.

78 Sobre el influjo del modelo miguelangelesco en la obra de Anchieta, véase García Gainza, 2008: 87-99.

79 Huidobro/González Negro, 2001: 112.

${ }^{80}$ Strauss/Shimura, 1986: 230-232. Huidobro/González Negro, 2001: 110-111. Hollstein, 1993, vol. V: 56.
} 


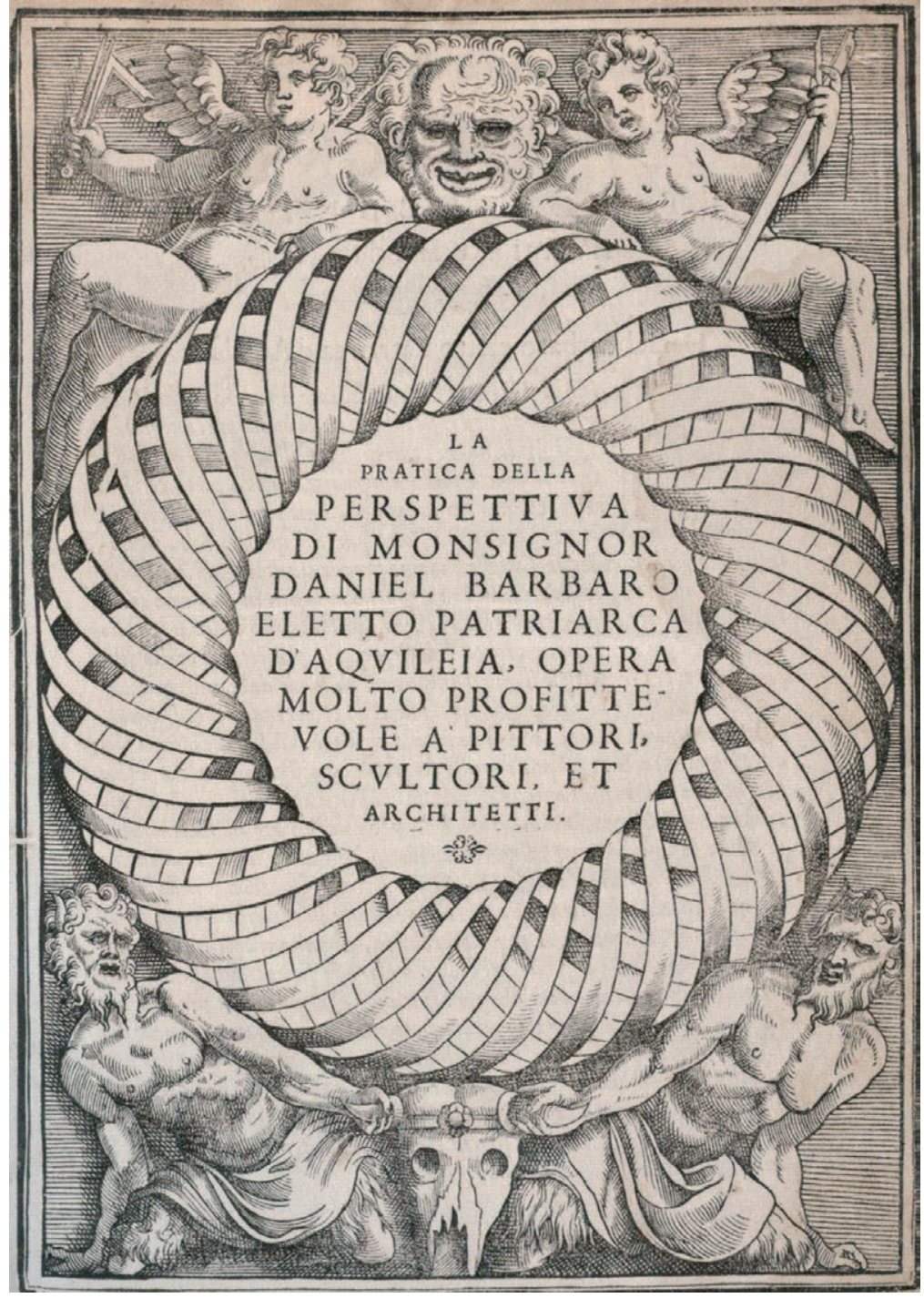

Fig. 8. Daniele Barbaro, La Pratica della Perspettiva, Venecia, 1569.

de Roma también fue reproducida en estampa, grabado que editó en 1554 Antonio de Salaman$\mathrm{ca}^{81}$.

Los proyectos arquitectónicos de Miguel Ángel igualmente fueron grabados, como el realizado para la basílica de San Pedro del Vaticano, de planta centralizada, que reprodujo en buril Dupérac, en estampas que muestran el diseño de la planta (1569), los alzados de la capilla mayor (1564) y otras partes del edifico, como vistas exteriores del mismo ${ }^{82}$. Artista francés que asimismo plasmó en la plancha la reforma de la colina del Capitolio, según muestran los grabados de 1567 con el plano de la plaza y los de 1568 y 1575 con la vista general del conjunto ${ }^{83}$.

Pisano también hizo acopio en Roma de seis "libros de basas y capiteles" para los artistas que tomaban estas ilustraciones como fuente gráfica de inspiración a la hora de

81 Tolnay, 1985: 80, fig. 180. González de Zárate, 1994, vol. VII: 92.

82 Tolnay, 1985: 113-121, figs. 274, 275, 277, 278. Bustamante/Marías, 1985, vol. I: 165-170.

83 Tolnay, 1985: 126-128, figs. 285 y 286. González de Zárate, 1993, vol. IV: 58.

${ }^{84}$ AGN, TR, Pr, Sig. 282591, f. 12r. 
acometer sus obras, tanto de tipo arquitectónico ${ }^{85}$, como en estructuras susceptibles de incorporar en su composición estos elementos, desde la mazonería de un retablo, sepulcros, fuentes, etc. La vaguedad de la anotación en el registro impide precisar más al respecto, por ejemplo, si se trataba de volúmenes con láminas ilustradas con elementos arquitectónicos, muy frecuentes en la época, como el referido en el listado de Antonio Lafrery de hacia 1573 conservado en la Biblioteca Marucelliana de Florencia bajo el título Libri di Cornice Capitelli et Basi cavato dalle vestige de gli Antichi, quale giornalmente si trovano in Roma ${ }^{86}$, o las estampas de igual temática publicadas por el comerciante Pietro de' Nobili entre 1580 y $1590^{87}$.

Por otra parte, Pisano pagó 20 reales por diez libros de perspectiva ${ }^{88}$, probablemente La Pratica della Perspettiva di Monsignor Daniel Barbaro (Venecia, 1569) (fig. 8), algunos de cuyos ejemplares fueron inventariados en la biblioteca de Musante en $1587^{89}$.

Otra entrada del registro de las mercadurías refiere 6 "libros de monstruos" 90 , sin precisar si se refería a volúmenes ilustrados con decoraciones fantasiosas a la manera de los grutescos ${ }^{91} \mathrm{o}$ sobre animales fantásticos, además de dos publicaciones de zoología dedicados a peces ${ }^{92}$, así como otro ítem con 10 libros de Amazonas ${ }^{93}$.

El documento refiere otros 7 libros de "Vasos del Pulidoro" 94 , es decir, volúmenes con los diseños de jarrones grabados por Cherubino Alberti en 1582 a partir de los dibujos de Polidoro da Caravaggio (†1543), para la decoración del Palacio Milesi de Roma (c. 1527)95 (fig. 9), uno de los más productivos artistas del primer manierismo asentado en Roma ${ }^{96}$ que alcanzó gran fama con la realización de escenas y ornamentos de inspiración clásica con los que decoró la fachada de numerosos palacios romanos, como el referido de Milesi.

Pisano también compró "ocho libros de labores o arabescos y grotescos" 97 . Al respecto, Tommaso Barlacchi, editor romano, publicó en 1541 una de las primeras series de veinticuatro grutescos grabadas por Enea Vico (1523-1567), que gozaron de gran trascendencia ${ }^{98}$, al igual que otros repertorios con este tipo de decoración renacentista facilitados por el impresor Lafrery ${ }^{99}$.

El listado de estampas y libros adquiridos por Antonio Pisano en Roma se cierra con la anotación de "dos libros de figuras de las Antigallas de Roma", por 24 reales ${ }^{100}$, es decir, uno de los numerosos volúmenes publicados con las obras y monumentos de la antigüedad en la ciudad ${ }^{101}$. En las décadas centrales del siglo XVI se descubrieron el Mausoleo de Augusto, los primeros restos del Ara Pacis, y se trabajó en el Palatino, en la Domus Aurea, el foro romano, la Via Apia, las termas de Caracalla y el foro de Trajano, entre otros. Descubrimientos que provocaron una gran actividad artística y editorial volcada en la reproducción calcográfica de dichos monumentos, como el volumen Libro D'Antonio Labacco Appartenente a L'Architettura, nel qual si figu-

85 Algunos ejemplos al respecto en el caso navarro y granadino en la época del renacimiento son: Tarifa Casti1la, 2011c: 463-480; 2014: 23-56.

86 Miller, 1999: 8-9, 184-191.

${ }^{87}$ Bustamante/Marías, 1985, vol. I: 165: 149-151.

88 AGN, TR, Pr, Sig. 282591, f. 11v.

89 Tarifa Castilla, 2011b: 36 .

90 AGN, TR, Pr, Sig. 282591, f. 12r.

91 Chastel, 2000: 39.

92 Sobre esta temática el zoólogo francés Guillaume Rondelet escribió el libro De Piscibus Marinis. Histoire des poissons (Lyon, 1554 y 1558), con ilustraciones que permitían reconocer las distintas especies marinas.

${ }_{93}$ AGN, TR, Pr, Sig. 282591, f. 12r.

94 AGN, TR, Pr, Sig. 282591, f. 12r.

95 Sobre esta serie de grabados véase, Miller, 1999: 244-254.

96 Vasari, 2002: 649-656. Freedberg, 1978: 220-225. Leone de Castris, 1988; 2001.

97 AGN, TR, Pr, Sig. 282591, f. 12r. Morel, 1997. Sobre los diferentes grabados impresos con este tipo de ornamentación en el siglo XVI, véase Miller, 1999: 68-110.

98 Spike, 1985. González de Zárate, 1999: 136-137.

99 Miller, 1999: 10.

100 AGN, TR, Pr, Sig. 282591, f. 12v.

101 Ejemplo significativo al respecto fue el libro de Antigualhas del portugués Francisco de Holanda, elaborado entre 1537 y 1540, cuyo original se encuentra en la Biblioteca del Monasterio de El Escorial. Holanda, 1940; 1989. 

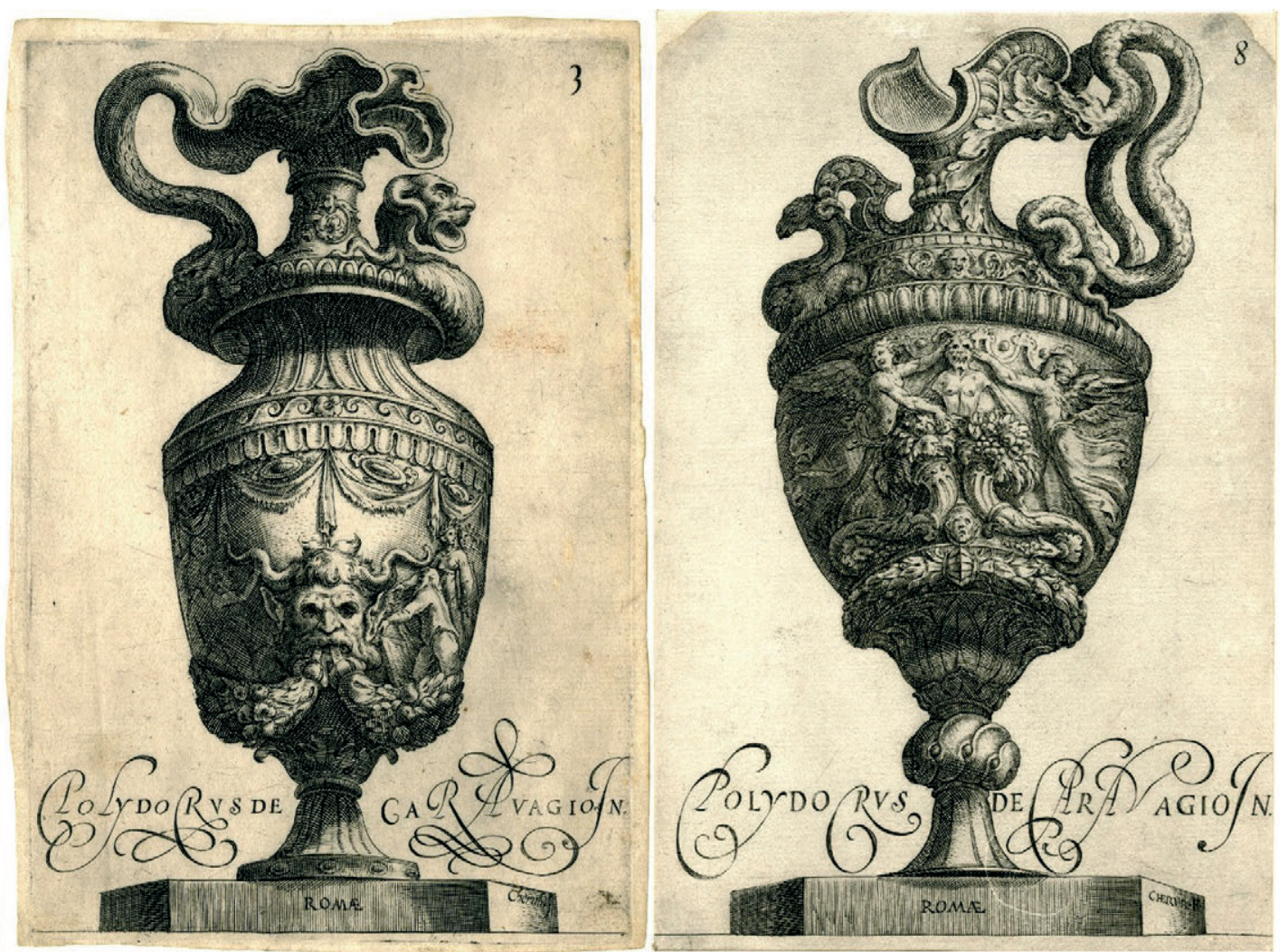

Fig. 9. Cherubino Alberti. Jarrones dibujados por Polidoro da Caravaggio. Londres, British Museum.

rano alcune notabili antiquita di Roma, impreso por primera vez en Roma en 1552 ${ }^{102}$; L'antichità di Roma de Andrea Palladio ${ }^{103}$, que fue publicada en 1554 en Roma por Vicenzo Lucrino, y el mismo año en Venecia por Matteo Pagan, una guía de viaje, con precisas plantas, alzados y secciones de las antigüedades de Roma; o la obra de Vicenzo Scamozzi, Discorsi sopra l'antichitá di Roma (Venecia, Francesco Ziletti, 1582), ilustrada con 40 grabados $^{104}$.

Otro de los volúmenes más famosos que dio a conocer las antigüedades de la ciudad de Roma a través de espléndidos grabados fue el titulado Speculum Romanae Magnificentiae, publicado por Antonio Lafrery en 1575, con 118 estampas ${ }^{105}$. Este editor y comerciante francés vivió en la ciudad entre 1544 y 1577, asociándose con el español Antonio de Salamanca en 1553, reuniendo los mejores grabados de monumentos y restos de la antigüedad ${ }^{106}$, como la escultura del Hércules Farnesio descubierta en las termas de Caracalla en 1546 y que grabó Jacob Bos en 1575 107, y las nuevas obras, como las acometidas en el Campidoglio. Según Bury, las estampas del Speculum se publicaron a partir de 1573 y se encuadernaban a gusto del comprador, pues los grabados varían de unos a otros ejemplares, tanto en su número como en la colocación dentro del libro ${ }^{108}$.

102 Esta publicación fue registrada en el inventario de la biblioteca de Musante, por lo que pudo ser uno de los libros que Pisano le trajo de Italia. Tarifa Castilla, 2011b: 35.

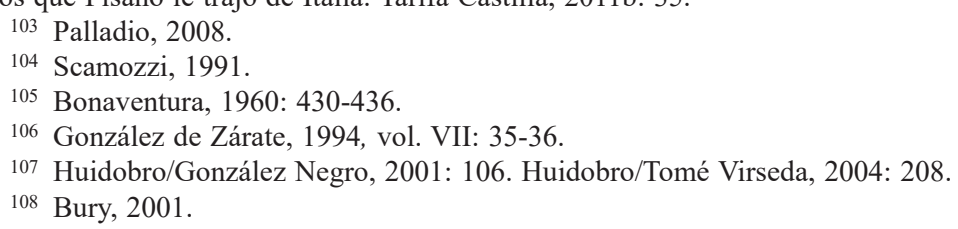


La edición de Lafrery del Speculum coincidió con la divulgación de otros libros editados con bellas estampas de antigüedades romanas y monumentos, como la del grabador francés residente en Roma, Étienne Dupérac ${ }^{109}$-quien precisamente había realizado la portada del Speculum-, como la publicación de I vestigi dell 'Antichità di Roma, raccolti e ritratti in prespectiva con ogni diligentia (Roma, 1575) ${ }^{110}$ con un total de 40 ilustraciones. Dupérac también acometió otras series grabadas, como un catálogo de estatuas y bustos de la antigüedad, así como el repertorio titulado Illustrations des fragments antiques, dividido en tres libros, mostrando el primero figuras $\mathrm{y}$ monumentos antiguos ${ }^{111}$.

Finalmente, quizás entre las ilustraciones que formaban parte de los libros de antigüedades adquiridos por Pisano en Roma se encontrasen algunos de Nicolás Beatrizet, conocido en gran parte por la difusión de las obras y arquitecturas que legó el mundo clásico romano ${ }^{112}$. Entre ellas se encuentran las dedicadas a la estatua ecuestre de Marco Aurelio, el grupo escultórico del Laocoonte, el Templo de la Fortuna Viril, el Panteón de Agripa, el mausoleo de Adriano, el teatro Marcelo, el Coliseo o el circo Flaminio ${ }^{113}$, algunas de las cuales fueron difundidas por el impresor Antonio de Salamanca ${ }^{114}$.

En definitiva, grabados que son reflejo de la cultura humanística de la época, en la que se conjugaron perfectamente las estampas de tipo devocional con las profanas. Representaciones y lecturas de tipo religioso que convivieron con imágenes de la Antigüedad clásica, de esculturas $\mathrm{y}$ edificios de época romana elegantemente ornamentados con decoraciones de grutescos, que tanto predicamento tuvieron en el siglo XVI, permitiendo así unir el mundo cristiano con el pagano, al que volvió sus ojos el renacimiento.

\section{La venta de las estampas y libros en España}

Pisano permaneció en Roma hasta el 22 de febrero de 1583, cuando inició el viaje de regreso, dirigiéndose por tierra a Génova, donde llegó el 15 de marzo para recoger al sobrino de Musante, Juan Bautista, y llevarlo a Pamplona junto a su tío. Mientras esperaba la llegada del joven, mandó iluminar y pintar 130 pliegos, por los que pagó 70 reales $^{115}$. En la ciudad también visitó a Miguel Musante, tío del ingeniero, al que entregó unas velas de la virgen de Nuestra Señora de Monserrat y unos peines grandes labrados, valorados en 10 reales ${ }^{116}$.

Tras partir de Génova el 25 de abril del presente año, Pisano llegó a Barcelona el 8 de mayo, donde recogió la mayor parte de la mercancía que desde Génova había mandado por barco. Desde allí se dirigió a Tarragona, Lérida y Tortosa, poblaciones en las que vendió los papeles que llevaba en un saco o fardelete, desplazándose también a Monzón, Zaragoza, Navarra y la localidad riojana de Nájera. A su paso por las mismas adquirió ciertas mercancías, como la compra que hizo en Lérida de ciertos libros para Musante, en los que empleó 233 ducados, o dos cruces de cristal miniadas ${ }^{117}$, productos que luego vendió en Pamplona a su regreso a la capital navarra el 12 de octubre de 1583, donde permaneció hasta el siguiente mes de enero, ocupándose de los asuntos económicos de Musante, mientras éste trabajaba en el palacio real de Olite.

Pisano vendió en Pamplona la mercancía adquirida, sin poder desplazarse a otras localidades para ello, ya que todos los domingos de los beneficios sacados en este negocio pagaba a los

109 Sobre este artista, véase Lurin, 2006.

110 Cámara Muñoz, 2007: 779.

111 González de Zárate, 1993, vol. IV: 53-54.

112 González de Zárate, 1999: 146.

113 González de Zárate, 1993, vol. I: 130-143. Algunos de estos grabados han sido reproducidos en Boorsch, 1982: 348-373.

114 Gonzalo Sánchez-Molero, 2007: 335-365.

115 AGN, TR, Pr, Sig. 282591, f. 14r.

116 AGN, TR, Pr, Sig. 282591, f. 29r.

117 AGN, TR, Pr, Sig. 282591, f. 27v. 
operarios que trabajaban en las obras del monasterio de Santa Eulalia que tenía contratadas Musante $^{118}$. Su permanencia en esta ciudad le ocasionó serias pérdidas en la venta de los artículos, ya que cuando partió para Zaragoza el 20 de enero de 1584, donde residió hasta principios del mes de mayo, otro mercader francés llamado Philibert Cancelado, con el que había coincidido en el viaje de regreso desde Italia, ya había dado salida a los mismos productos que él ofrecía en esta localidad, por lo que tuvo que rebajar el precio de los mismos, como los papeles que llevaba consigo ${ }^{119}$.

En el referido desplazamiento a Zaragoza de comienzos de 1584, Pisano cayó enfermo a su paso por Huesca, donde vendió al librero Diego López cerca de mil pliegos de papel de los que había adquirido en Roma ${ }^{120}$. En este viaje le entregaron "un libro figurado de pliego de manu escripto para el dicho Juan Luys [Musante] por los loores y buena fama que del havia dado y no porque jamas lo conosciera,... del qual libro me davan en Çaragoza mas de sesenta ducados por ser el principal o original" 121 , concretamente, "un libro manu escripto figurado de mano de maestre Thomas" 122 , si bien el documento no refiere nada más, ni la materia del mismo o su posible cronología, lo que nos impide ahondar más al respecto. Ante la imposibilidad de identificar al referido maestro Tomás, simplemente recordamos que hasta el año de 1579 está documentado trabajando en la localidad oscense un pintor italiano llamado Tomás Peliguet (doc. 1538-79), de quien el teórico barroco Jusepe Martínez refiere que hizo abundantes "dibujos para pintores, escultores, talladores de grotescos, bordadores, arquitectos y fábricas de iglesia", diseños que, como corroboran las fuentes documentales, fueron empleados en la contratación de todo tipo de objetos artísticos ${ }^{123}$, y que estarían en la línea del libro con dibujos entregado a Pisano del hasta ahora incógnito artista.

\section{BIBLIOGRAFÍA}

Bénézit, Emmanuel (1966): Dictionnaire critique et documentaire des peintres, sculpteurs, dessinateurs et graveurs de tous les temps et de tous les pays, vol. VI. Paris: Gründ.

Bersier, Jean-Eugène (1990): La gravure. Les procédés, l'histoire. Paris: Berger-Levrault.

Bierens de Haan, Johann Catharinus Justus (1948): L'ouvre gravé de Cornelis Cort, graveur hollandains 1533-1578. La Haye: Martinus Nyhoff.

Bonaventura, Maria Antonietta (1960): “L'industria e il comercio delle incisione nella Roma del'500”. En: Studi Romani, n. ${ }^{\circ} 8$, Roma, pp. 430-436.

Boorsch, Suzanne (1982): The Illustrated Bartsch. Italian master of the sixteenth century. Nueva York: Arabis Books, vol. 29.

Boorsch, Suzanne/Lewis, Michal/Lewis, R. E. (1985): The Engrawings of Giorgio Ghisi. Nueva York: The Metropolitan Museum of Art.

Boorsch, Suzanne/Spike, John (eds.) (1986): The Illustrated Bartsch. Italian Artists of the Sixteenth Century. Nueva York: Arabis Books, vol. 31.

Bosch, Maria (2013): "Vespasiano Gonzaga Colonna, Reals Crides i Edictes relativos a la Ciudad y Reino de Valencia". En: Lemir: Revista de Literatura Española Medieval y del Renacimiento, n. ${ }^{\circ} 17$, Valencia, pp. 1023-1094.

Burns, Howard (1988): "Pirro Ligorio's reconstruction of ancient Rome: the Anteiquae Urbis Imago of 1561". En: Gaston, Robert W. (ed.): Pirro Ligorio, artist and antiquarian. Milano: Silvana, pp. 19-92.

Bury, Michael (2001): The print in Italy, 1550-1620. London: British Museum Press.

Bury, Michael/Lockett, Katherine (2011): "Béatrizet's Last Juggement, after Michelangelo, in the Cortauld Gallery". En: Print Quarterly, vol. 28 (n. ${ }^{\circ}$ 3), Londres, pp. 266-271.

Bustamante, Agustín/Marías, Fernando (1985): "El Escorial y la cultura arquitectónica de su tiempo". En: Santiago Páez, Elena (coord.): El Escorial en la Biblioteca Nacional. Madrid: Ministerio de Cultura, vol. I, pp. 115-219.

\footnotetext{
118 AGN, TR, Pr, Sig. 282591, ff. 14r-18v.

119 AGN, TR, Pr, Sig. 282591, f. 23v.

120 AGN, TR, Pr, Sig. 282591, f. 20v.

121 AGN, TR, Pr, Sig. 282591, f. 18r.

122 AGN, TR, Pr, Sig. 282591, f. 25r.

123 Sobre este artista véase, Criado Mainar, 1996: 540-550.
} 
Cámara Muñoz, Alicia (2007): “De España a Roma. Peregrinar en el Siglo de Oro”. En: Hernando Sánchez, Carlos José (coord.): Roma y España. Un crisol de la cultura europea en la Edad Moderna. Madrid: Sociedad Estatal para la Acción Cultural Exterior, vol. 2, pp. 767-780.

Chastel, André (2000): El grutesco. Madrid: Akal.

Civale, Gianclaudio (2010): "La formazione e l'ascesa di Vespasiano Gonzaga Colonna, un principe italiano al servizio degli Asburgo (1540-1568)”. En: Martínez Millán, J./Rivero Rodríguez, M. (coords.): Centros de poder italianos en la monarquía hispánica (siglos XV-XVIII). Madrid: Ediciones Polifemo, vol. 1, pp. 163-206.

Coffin, David R. (2003): Pirro Ligorio. The Renaissance Artist, Architect, and Antiquarian. University Park: Penn State University Press.

Criado Mainar, Jesús (1996): Las artes plásticas del Segundo Renacimiento en Aragón: pintura y escultura 1540-1580. Tarazona, Centro de Estudios Turiasonenses.

Criado Mainar, Jesús (2013): "Daniel Martínez en el taller de Felipe de Cáceres y la renovación en clave flamenca de la pintura zaragozana en la década de 1570". En: Álvaro Zamora, María Isabel/Lomba Serrano, Concepción/Pano Gracia, José Luis (coords.): Estudios de Historia del Arte. Libro homenaje a Gonzalo M. Borrás Gualis. Zaragoza: Institución Fernando el Católico, pp. 287-300.

Docampo, Javier/Riello, José (coords.) (2014): La biblioteca del Greco. Madrid: Museo Nacional del Prado.

Fernández del Hoyo, María Antonia (1991): “Datos para la biografía de Juan de Juni”. En: Boletín del Seminario de Estudios de Arte y Arqueología, n. ${ }^{\circ}$ 57, Valladolid, pp. 333-340.

Fernández Gracia, Ricardo/Echeverría Goñi, Pedro Luis/García Gainza, María Concepción (2005): El arte del Renacimiento en Navarra. Pamplona: Gobierno de Navarra.

Freedberg, S. J. (1978): Pintura en Italia, 1500-1600. Madrid: Cátedra.

Frutaz, Amato Pietro (1962): Le piante di Roma. Roma: Instituto Nazionale di Studi Romani, vol. II.

García Gainza, María Concepción (2008): Juan de Anchieta, escultor del Renacimiento. Pamplona: Fundación Arte Hispánico, Gobierno de Navarra.

García Medina, Alicia (1999): "Formación y mecenazgo de un destacado noble de la corte de Felipe II: don Bernardino de Cárdenas. Duque de Maqueda”. En: El Arte en las Cortes de Carlos V y Felipe II, IX Jornadas de Arte. Madrid: CSIC, pp. 393-407.

Garriga Riera, Joaquim (1999): "Pietro Paolo de Montalbergo. Pintor italià, ciutadà de Barcelona". En: Miscel·lània en Homenatge a Joan Ainaud de Lasarte. Barcelona, vol. II, pp. 5-40.

Gnann, Achim (1999): “268/269. Il martirio di San Lorenzo”. En: Oberhuber, Konrad (ed.): Roma e lo stile classico di Raffaello. 1515-1527. Milán: Electa, pp. 358-359.

Gnann, Achim (comp.) (2004): Miguel Ángel y su tiempo. Obras maestras de la Albertiana: Milán: Electa.

Goltzius, Hubert (1560): Los vivos retratos de todos los Emperadores, desde Iulio Cesar hasta el emperador Carlos Vy don Fernando su hermano. Amberes: Imp. Egidio Copenio de Dist.

Gómez-Ferrer Lozano, Mercedes (2013): "El maestro genovés Juan Luis de Musante (act. 1570-1587) y su presencia en Orihuela. Reflexiones en torno a algunos maestros itinerantes en la segunda mitad del siglo XVI". En: Anuario del Departamento de Historia y Teoría del Arte, n. ${ }^{\circ} 25$, pp. 43-60.

González de Zárate, Jesús María (1992-1996): Real Colección de Estampas de San Lorenzo de El Escorial, vols. I-X. Vitoria: Instituto Municipal de Estudios Iconográficos Ephialte.

González de Zárate, Jesús María (1999): Artistas grabadores en la Edad del Humanismo. Pamplona: Liber.

Gonzalo Sánchez-Molero, José Luis (2007): "Antonio de Salamanca y los libros españoles en la Roma del siglo XVI". En: Roma y España. Un crisol de la cultura europea en la Edad Moderna. Madrid: Sociedad Estatal para la Acción Cultural Exterior, vol. 1, pp. 335-365.

Hernando Sánchez, Carlos José (1999): "Estar en nuestro lugar, representando nuestra propia persona. El gobierno virreinal en Italia y la Corona de Aragón bajo Felipe II”. En: Belenguer Cebria, E. (coord.): Felipe II y el Mediterráneo, vol. III, La monarquía y los reinos (I). Madrid: Sociedad Estatal para la Conmemoración de los Centenarios de Felipe II y Carlos V, pp. 215-338.

Hirst, Michael (1989): Michelangelo and his Drawings. New Haven: Yale University Press.

Holanda, Francisco de (1940): Os desenhos das antigualhas que vio Francisco d'Ollanda, pintor portugués (...15391549) (ed. Elías Tormo). Madrid: Hauser y Menet.

Holanda, Francisco de (1989): Álbum dos Desenhos das Antigualhas. Lisboa: Livros Horizonte.

Hollstein, Friedrich Wilhelm Heinrich (1993): The New Hollstein. Dutch and Flemish etchings, engravings and woodcuts, 1450-1700. Roosendaal: Koninklijke van Pooll, vol. V.

Huidobro, Concha/González Negro, Irene (2001): El arte del grabado flamenco y holandés. De Lucas van Leyden a Martin de Vos. Madrid: Electa.

Huidobro, Concha/Tomé Virseda, Consuelo (2004): Grabados flamencos y holandeses del siglo XVI. Obras escogidas de la Biblioteca Nacional. Madrid: Biblioteca Nacional.

Insolera, Italo (1996): Roma: immagini e realtà dal X al XX secolo. Roma: Laterza.

Joannides, Paul (2003), Michel-Ange, élevès et copistes. Dessins italiens du Musée du Louvre. Paris: Reunion des Musées Nationaux.

Labrot, Gérard (1987): L'image de Rome. Une arme pour la Contre-Réforme 1534-1677. Paris: Editions Champ Vallon.

Leone de Castris, Pierluigi (1988): Polidoro da Caravaggio fra Napoli e Messina. Milán: Mondadori.

Leone de Castris, Pierluigi (2001): Polidoro da Caravaggio. L`opera completa. Nápoles: Electa. 
Lurin, Emmanuel (2006): Étienne Dupérac, graveur, peintre et architecte (vers 1535?-1604). Un artiste-antiquaire entre l'Italie et la France. Tesis doctoral, Université Paris-Sorbonne.

Massari, Stefania (1980): Incisori Mantuani del 500, Giovan Battista, Adamno, Diana Scultori e Giorghio Ghisi dalle collezioni del Gabinetto Nazionale delle Stampe e dela Calcografia Nazionale. Roma: De Luca Editore.

Miller, Elizabeth (1999): 16 th-century Italian ornament prints in the Victoria and Albert Museum. London: V\&A Publications.

Morel, Philippe (1997): Les grotesques: les figures de l'imaginaire dans la peinture italienne de la fin de la Renaissance. Paris: Flammarion.

Palladio, Andrea (2008): Las antigüedades de Roma. Madrid: Akal.

Pijoán, José (1966): "Renacimiento romano y veneciano. Siglo XVI". En: Summa Artis, Historia General del Arte, vol. XIV. Madrid: Espasa-Calpe.

Pinci, Enzo (1992): Pirro Ligorio, architetto napoletano: appunti critici. Roma: Edizioni Kappa.

Rivero Gracia, Pilar (2005): "Mercaderes y finanzas en la Europa del siglo XVI: material teórico para elaborar una unidad didáctica". En: Clio: History and History Teaching, 31, pp. 1-53.

San Vicente, José Ignacio/Santos Yanguas, Juan (2005): "Algunas consideraciones sobre las grabaciones de las monedas en el Libro de Enea Vico Le imaginni con tutti riversi trovati et le vite de gli imperatori tratte delle medaglie et dalle historie de gli antichi”. En: Alfaro Ansín, Carmen/Marcos Alonso, Carmen/Otero Morán, Paloma (eds.): XIII Congreso Internacional de Numismática. Actas. Madrid: Ministerio de Cultura, vol. 1, pp. 105-111.

Scamozzi, Vincenzo (1991): Discorsi sopra l'antichitá di Roma, 1582. Milano: Il Polifilo.

Silva Maroto, Pilar (1991): "La utilización del grabado por los pintores españoles del siglo XVI". En: Jornadas sobre el Renacimiento español, Principe de Viana, n. ${ }^{\circ}$ 99, Pamplona, pp. 311-210.

Spike, John (ed.) (1985): The Illustrated Bartsch. Italian Masters of the Sixteenth Century: Enea Vico. Nueva York: Arabis Books, vol. 30.

Strauss, Walter L./Shimura, Tomoko (1986): The Illustrated Bartsch vol. 52. Netherlandish artists. Cornelius Cort. Nueva York: Abaris Books.

Switf, Michael (2008): Ciudades del Renacimiento: Civitates Orbis Terrarum. Königswinter: H. F. Ullmann.

Tarifa Castilla, María Josefa (2008): "El maestro italiano Juan Luis de Musante y su proyección en la arquitectura navarra del siglo XVI". En: García Gainza, M.C./Fernández Gracia, R. (coords.): Cuadernos de la Cátedra de Patrimonio y Arte Navarro, $n .^{\circ} 3$, Presencia e influencias exteriores en el Arte Navarro. Pamplona: Cátedra de Patrimonio y Arte Navarro, pp. 605-620.

Tarifa Castilla, María Josefa (2009): "La iglesia parroquial de Lerín: ejemplo excepcional de arquitectura manierista en Navarra”. En Príncipe de Viana, . $^{\circ}$ 246, pp. 7-39.

Tarifa Castilla, María Josefa (2010): "La iglesia parroquial de Nuestra Señora de la Asunción de Lerín”. En: Garnica Cruz, A./Ona González, J.L. (coords.): Lerín: Historia, Naturaleza, Arte. Zaragoza: Ayuntamiento de Lerín, pp. 185210.

Tarifa Castilla, María Josefa (2011a): "Juan Luis de Musante, maestro mayor de las obras de la ciudadela de Pamplona". En: Artigrama, n. ${ }^{\circ}$ 26, pp. $583-602$.

Tarifa Castilla, María Josefa (2011b): "La biblioteca del genovés Juan Luis de Musante (1587), maestro mayor de obras reales de Felipe II". En: Anuario del Departamento de Historia y Teoría del Arte, n. ${ }^{\circ} 23$, pp. 31-46.

Tarifa Castilla, María Josefa (2011c): "La cultura arquitectónica de los artistas en la Navarra del siglo XVI". En: VII Congreso General de Historia de Navarra, Príncipe de Viana, 253, pp. 463-480.

Tarifa Castilla, María Josefa (2013): "Intervenciones arquitectónicas renacentistas en los palacios reales de Pamplona y Olite". En: Mínguez, V.: Las artes y la arquitectura del poder. Castelló de la Plana: Universitat Jaume I, pp. 889-906.

Tarifa Castilla, María Josefa (2014): "Fuentes gráficas de inspiración y modelos de difusión de la arquitectura granadina del Renacimiento". En: Cruz Cabrera, J. P. (coord.): Arte y cultura en la Granada renacentista y barroca. Relaciones e influencias. Granada: Universidad de Granada y Departamento de Bienes Culturales de la Universidad de Palermo, pp. 19-52.

Tarifa Castilla, María Josefa (2015): "Ingenieros y maestros de obras del recinto fortificado de Pamplona en el siglo XVI". En: International Conference on Fortified Heritage: Management and Sustainable Development. FORTIUS Pamplona-Bayonne Project, Pamplona 15-17 de octubre de 2014. Pamplona: Ayuntamiento de Pamplona, pp. 517-534.

Tolnay, Charles de (1975-1980): Corpus dei disegni di Michelangelo. Novara: Istituto Geografico de Agostini, 4 vols.

Tolnay, Charles de (1985): Miguel Ángel, escultor, pintor y arquitecto. Madrid: Alianza Editorial.

Vasari, Giorgio (1568): Delle Vite de'Piu Eccelenti Pittori, Scultori et Architettori. Florencia: Apresso i Giunti.

Vasari, Giorgio (1998): Le opere di Giorgio Vasari con nuove annotazioni e commenti di Gaetano Milanesi. Firenze: La Lettere, vol. VI.

Vasari, Giorgio (2002): Las vidas de los más excelentes arquitectos, pintores y escultores italianos desde Cimabue a nuestros tiempos (eds. Luciano Bellosi y Aldo Rossi). Madrid: Cátedra.

Fecha de recepción: 11-VI-2015

Fecha de aceptación: 18-II-2016 